\title{
Challenges and opportunities for improving the landscape for Lewy body dementia clinical trials
}

Jennifer G. Goldman ${ }^{1 *}$ D, Leah K. Forsberg², Bradley F. Boeve², Melissa J. Armstrong³, David J. Irwin", Tanis J. Ferman ${ }^{5}$, Doug Galasko ${ }^{6}$, James E. Galvin7, Daniel Kaufer ${ }^{8 \wedge}$, James Leverenz ${ }^{9}$, Carol F. Lippa ${ }^{10}$, Karen Marder ${ }^{11}$, Victor Abler ${ }^{12}$, Kevin Biglan ${ }^{13}$, Michael Irizarry ${ }^{14}$, Bill Keller $^{12}$, Leanne Munsie ${ }^{13}$, Masaki Nakagawa ${ }^{15}$, Angela Taylor ${ }^{16}$ and Todd Graham ${ }^{16}$

\begin{abstract}
Lewy body dementia (LBD), including dementia with Lewy bodies and Parkinson's disease dementia, affects over a million people in the USA and has a substantial impact on patients, caregivers, and society. Symptomatic treatments for LBD, which can include cognitive, neuropsychiatric, autonomic, sleep, and motor features, are limited with only two drugs (cholinesterase inhibitors) currently approved by regulatory agencies for dementia in LBD. Clinical trials represent a top research priority, but there are many challenges in the development and implementation of trials in LBD. To address these issues and advance the field of clinical trials in the LBDs, the Lewy Body Dementia Association formed an Industry Advisory Council (LBDA IAC), in addition to its Research Center of Excellence program. The LBDA IAC comprises a diverse and collaborative group of experts from academic medical centers, pharmaceutical industries, and the patient advocacy foundation. The inaugural LBDA IAC meeting, held in June 2019, aimed to bring together this group, along with representatives from regulatory agencies, to address the topic of optimizing the landscape of LBD clinical trials. This review highlights the formation of the LBDA IAC, current state of LBD clinical trials, and challenges and opportunities in the field regarding trial design, study populations, diagnostic criteria, and biomarker utilization. Current gaps include a lack of standardized clinical assessment tools and evidence-based management strategies for LBD as well as difficulty and controversy in diagnosing LBD. Challenges in LBD clinical trials include the heterogeneity of LBD pathology and symptomatology, limited understanding of the trajectory of LBD cognitive and core features, absence of LBD-specific outcome measures, and lack of established standardized biologic, imaging, or genetic biomarkers that may inform study design. Demands of study participation (e.g., travel, duration, and frequency of study visits) may also pose challenges and impact trial enrollment, retention, and outcomes. There are opportunities to improve the landscape of LBD clinical trials by harmonizing clinical assessments and biomarkers across cohorts and research studies, (Continued on next page)
\end{abstract}

\footnotetext{
* Correspondence: jgoldman02@sralab.org

Daniel Kaufer is deceased.

'Parkinson's Disease and Movement Disorders Program, Shirley Ryan AbilityLab and Departments of Physical Medicine and Rehabilitation and Neurology, Northwestern University Feinberg School of Medicine, 355 E. Erie Street, Chicago, IL 60611, USA

Full list of author information is available at the end of the article
}

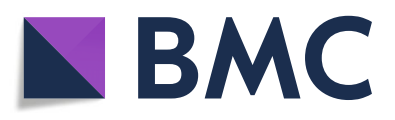

(c) The Author(s). 2020 Open Access This article is licensed under a Creative Commons Attribution 4.0 International License, which permits use, sharing, adaptation, distribution and reproduction in any medium or format, as long as you give appropriate credit to the original author(s) and the source, provide a link to the Creative Commons licence, and indicate if changes were made. The images or other third party material in this article are included in the article's Creative Commons licence, unless indicated otherwise in a credit line to the material. If material is not included in the article's Creative Commons licence and your intended use is not permitted by statutory regulation or exceeds the permitted use, you will need to obtain permission directly from the copyright holder. To view a copy of this licence, visit http://creativecommons.org/licenses/by/4.0/. The Creative Commons Public Domain Dedication waiver (http://creativecommons.org/publicdomain/zero/1.0/) applies to the data made available in this article, unless otherwise stated in a credit line to the data. 
(Continued from previous page)

developing and validating outcome measures in LBD, engaging the patient community to assess research needs and priorities, and incorporating biomarker and genotype profiling in study design.

Keywords: Biomarker, Clinical trial readiness, Dementia, Lewy bodies, Neuropsychology, Outcome measure, Parkinson's disease, Parkinsonism, Primary endpoint, Randomized controlled trial

\section{Introduction}

Lewy body dementia (LBD), comprised of dementia with Lewy bodies (DLB) and Parkinson's disease dementia (PDD), affects approximately 1.4 million in the USA and carries substantial public health impact [1,2]. Currently available symptomatic treatments for LBD vary in their effectiveness and symptom target (i.e., cognitive impairment, parkinsonism, psychosis, among others). Diseasemodifying and curative treatments are lacking. Clinical trials for LBD are prioritized in the Alzheimer's Disease (AD)-Related Dementia (ADRD) Summit recommendations [3], but randomized clinical trials in LBD are few, particularly compared to AD and Parkinson's disease (PD) without dementia $[4,5]$. In order to advance the field of LBD clinical trials, the Lewy Body Dementia Association (LBDA) developed a Research Centers of Excellence (RCOE) program in 2017, bringing together expert clinicians and researchers across the USA with a goal of becoming a clinical trials-ready network [6]. In 2019, the LBDA launched the Industry Advisory Council (IAC) to provide a collaborative forum for discussion among LBD experts, pharmaceutical industries, governmental agencies, and the nonprofit LBDA to address challenges and opportunities for LBD clinical trials. The inaugural LBDA IAC meeting, held in June 2019, focused on key gaps and challenges in clinical trial design and implementation in LBD. In this review, we discuss the formation of the IAC, current state of LBD clinical trials, and challenges and opportunities for optimizing future clinical trials in LBD.

\section{The need for partnerships and formation of the LBDA IAC}

Over the years, partnerships have developed among academic medical experts, patient advocacy groups, pharmaceutical industries, and government bodies for neurological and other diseases to address clinical and research challenges. These collaborations have increased awareness and diagnosis of the condition, improved access to expert care, fostered interest for drug development, and promoted clinical trial site readiness, all critically important for increasing the likelihood of recruitment and completion of clinical trials $[7,8]$. These partnerships may help reduce barriers in clinical research such as shortening the long latency between drug development and Food and Drug Administration (FDA) approval, reducing the frequency of failed drug trials, and potentially lessening the economic investment for drug development [9]. As such, the LBDA formed an Industry Advisory Council including invited members from the RCOE network and Scientific Advisory Council with clinical and research expertise in movement disorders neurology, cognitive neurology, and neuropsychology; pharmaceutical industries known to be currently sponsoring or considering phase 2 or 3 clinical trials for LBD; governmental agencies; and the LBDA foundation.

\section{Diagnostic criteria and standards of care for LBD}

LBD remains underdiagnosed or misdiagnosed, which can delay appropriate clinical management and presents challenges for LBD clinical trials. Difficulty in symptom recognition, fluctuations in cognitive and functional presentations, and differences in specialty access and evaluations across healthcare systems contribute to these challenges [10-12]. The DLB diagnostic criteria, revised in 2017, define essential cognitive and core clinical features and provide a framework to incorporate indicative and supportive biomarkers of diagnosis [13]. The clinical diagnostic criteria for PDD, published in 2007, include features that distinguish dementia in the context of established PD from AD or other dementias [14]. Both DLB and PDD diagnoses are listed in the Diagnostic and Statistical Manual of Mental Disorders (DSM)-5 as major neurocognitive disorders [15]. Challenges and controversy, however, remain in dividing LBD into DLB and PDD given overlapping clinical symptoms, biomarker findings, and underlying pathology, with the "1-year" rule being a primary distinguishing factor. In addition, criteria for mild cognitive impairment (MCI) in PD and in DLB have been proposed [16, 17].

Additional tools have been developed to assist with diagnosing and characterizing DLB since past diagnostic criteria historically have had variable sensitivity in clinical practice (12-88\%) [18]. These tools include the Lewy Body Composite Risk Score (LBCRS) [18], LBDA's diagnostic symptom checklist [19], National Alzheimer's Coordinating Center (NACC) DLB module [20], and DIAMOND-Lewy Toolkit [10, 21]. The LBCRS, a relatively short questionnaire and validated in a dementia population, discriminates between DLB and AD and between $\mathrm{MCI}$ in these two groups. The LBDA checklist provides a symptom list that people diagnosed with LBD 
or their caregivers can bring to a physician and a summary of DLB criteria. The NACC DLB module, developed in 2016 to accompany the Uniform Data Set used in NIA AD Centers, aims to better characterize LBD with a standardized clinical and cognitive battery. The DIAMOND-Lewy Toolkit was developed in the UK to assist with diagnosing DLB in clinical practice and uses brief assessments deemed feasible by dementia and PD clinicians. Harmonizing clinical assessment tools and application of diagnostic criteria across DLB and PDD cohorts in observational studies and across international clinical and research efforts remains a priority and is critical to LBD clinical trials.

At present, there is no consensus for a standard of care for LBD, and evidence-based strategies are limited. The UK DIAMOND-Lewy Management Toolkit provides clinicians with a management overview, symptom management summaries, and reference guide, and several recent reviews highlight management strategies [22-25]. Regularly updated evidence-based reviews are available for PD motor and non-motor symptoms, but are lacking in LBD, especially for DLB [26]. Medications for dementia have been studied in several double-blind, placebo-controlled studies for LBD, with donepezil approved for DLB in Japan and rivastigmine approved for PDD in the USA and European Union. Clinical care of LBD is complex due to a wide range of symptoms (cognitive impairment/dementia, parkinsonism, mood disorders, psychosis, apathy, autonomic dysfunction, sleep disturbances, and fluctuations), and treatment of one or more of these clinical features may exacerbate existing symptoms or produce new ones. The heterogeneity of LBD symptoms and presentations not only make a uniform standard of care difficult, but also underlie some clinical trial design challenges regarding study focus, subject criteria, and outcome measures.

\section{Current state of clinical trials in LBD}

Despite the emphasis in NIH ADRD recommendations and increased numbers of clinical trials for LBD in recent years, randomized controlled trials in LBD lag behind those conducted in other neurodegenerative diseases (e.g., AD, non-demented PD), do not yet address the full range of LBD symptoms, and primarily focus on symptomatic rather than disease-modifying therapies. Several reviews discuss recent clinical trials in LBD $[4,5,22,24,27]$. In one review of DLB trials listed in ClinicalTrials.gov from 2002 to 2019, there were 87 registered trials, and of those, 30 trials studied pharmacological agents or devices [5]. There were 9 pharmacological agents and one device studied in 22 trials. Most trials were phase 2 or post-marketing or exploratory studies with a smaller number of phase $2 / 3$ or pilot device studies. All focused on cognition, psychosis, or sleep symptoms, and one trial focused on motor symptoms. Fewer than 10 trials in LBD have been completed between 2016 and 2020, and recent/ongoing LBD trials remain largely focused on cognitive outcomes but may utilize novel or repurposed agents (Table 1). To date, no trials have studied fluctuations, dysautonomia, agitation, or apathy in LBD.

\section{Optimizing clinical trial design in LBD (Table 2, Fig. 1) Study population}

Fundamental considerations for LBD trials include whether to combine DLB and PDD participants in the same trial or to conduct separate trials for DLB and for PDD. Despite shared clinical, neurobiological, and pathological features, DLB and PDD groups may demonstrate differing treatment responses. DLB patients receiving memantine showed greater improvement on $\mathrm{AD}$ Cooperative Study-Clinical Global Impression of Change (ADCS-CGIC) scores than those receiving placebo, but the PDD group failed to show benefit vs. placebo; additionally, the DLB, but not the PDD, group showed significant improvement on Neuropsychiatric Inventory (NPI) scores [28]. AD co-pathology represents an important source of clinically meaningful biological heterogeneity in LBD phenotype and may influence clinical response. The development of biomarkers and clinicalpathological correlations are needed to help separate clinical differences between PDD and DLB from underlying biological differences.

Defining the LBD trial population requires decisions regarding which definitions and diagnostic criteria to use. To date, trials have primarily utilized DLB consensus criteria (3rd revision) [29] and the DSM-IV-TR for PDD. Very few trials have used the 2007 PDD criteria, and some trials utilize ranges or cutoff scores for the Mini-Mental State Examination (MMSE), Clinical Dementia Rating Scale, or Montreal Cognitive Assessment for enrollment [14]. Study criteria often do not specify the inclusion of probable vs. possible DLB. Defining PDD by DSM criteria may bias towards amnestic phenotypes, which may potentially reflect greater underlying $\mathrm{AD}$ co-pathology, and thus, influence treatment effects [30]. In LBD clinical trials, inclusion criteria have been based on clinical features rather than adjunctive biomarkers. In contrast, in some PD clinical trials, dopamine transporter scans are incorporated, and imaging and biofluid markers are commonly utilized in clinical trials for $\mathrm{AD}$ and the $\mathrm{MCI}$ stage of $\mathrm{AD}$. With growing interest in disease-modifying strategies or symptomatic therapies for milder or earlier stages, how to best design trials for prodromal or MCI stages of PD (PD-MCI) or DLB (MCI-LB) merits consideration. While several trials 
Table 1 Selected recent/ongoing and completed LBD clinical trials 2016-2020

\begin{tabular}{|c|c|c|c|c|c|c|}
\hline $\begin{array}{l}\text { ClinicalTrials.gov } \\
\text { identifier }\end{array}$ & Population & $\begin{array}{l}\text { Drug/ } \\
\text { intervention }\end{array}$ & Mechanism & $\begin{array}{l}\text { Trial } \\
\text { design }\end{array}$ & Primary outcome & $\begin{array}{l}\text { Results for primary } \\
\text { outcome }\end{array}$ \\
\hline NCT03305809 & DLB or PDD & Mevidalen & $\begin{array}{l}\text { D1 positive allosteric } \\
\text { modulator (D1PAM) }\end{array}$ & $\begin{array}{l}\text { Phase 2, } \\
\text { DB-PC }\end{array}$ & $\begin{array}{l}\text { CDR computerized cognition } \\
\text { battery continuity of attention } \\
\text { composite score }\end{array}$ & Ongoing \\
\hline NCT03413384 & PDD & Ceftriaxone & $\begin{array}{l}\text { Glutamatergic activity, } \\
\text { excitotoxicity reduction }\end{array}$ & $\begin{array}{l}\text { Phase 2, } \\
\text { DB-PC }\end{array}$ & ADAS-Cog & Ongoing \\
\hline NCT02914366 & PDD & Ambroxol & $\begin{array}{l}\text { Raise beta-Gcase, lower a- } \\
\text { synuclein }\end{array}$ & $\begin{array}{l}\text { Phase 2, } \\
\text { DB-PC }\end{array}$ & ADAS-Cog, ADCS-CGIC & Ongoing \\
\hline NCT03774459 & PDD & Anavex2-73 & $\begin{array}{l}\text { Cellular homeostasis } \\
\text { restoration via sigma-1 } \\
\text { and muscarinic receptors }\end{array}$ & $\begin{array}{l}\text { Phase 2, } \\
\text { DB-PC }\end{array}$ & $\begin{array}{l}\text { CDR computerized cognition } \\
\text { battery continuity of attention } \\
\text { composite score, safety }\end{array}$ & Ongoing \\
\hline NCT03713957 & $\begin{array}{l}\text { PDD or PD- } \\
\mathrm{MCl}\end{array}$ & GRF6021 & Plasma-derived product & $\begin{array}{l}\text { Phase 2, } \\
\text { DB-PC }\end{array}$ & Safety & Ongoing \\
\hline NCT03467152 & DLB & E2027 & $\begin{array}{l}\text { Selective phosphodiesterase } \\
\text { inhibitor type } 9\end{array}$ & $\begin{array}{l}\text { Phase 2, } \\
\text { DB-PC }\end{array}$ & MoCA, CIBIC+ & Ongoing \\
\hline NCT04002674 & DLB & Nilotinib & Tyrosine kinase inhibitor & $\begin{array}{l}\text { Phase 2, } \\
\text { DB-PC }\end{array}$ & Safety, tolerability & Ongoing \\
\hline NCT02669433 & DLB & Intepiridine & 5HT-6 antagonist & $\begin{array}{l}\text { Phase 2, } \\
\text { DB-PC }\end{array}$ & UPDRS Part 3 & Negative \\
\hline NCT01023672 & DLB & Armodafinil & Unknown & $\begin{array}{l}\text { Open-label, } \\
\text { pilot }\end{array}$ & ESS, MWT & Positive \\
\hline NCT01340001 & DLB & $\begin{array}{l}\text { DBS of nucleus } \\
\text { basalis of } \\
\text { Meynert }\end{array}$ & Neuromodulation & $\begin{array}{l}\text { Open-label, } \\
\text { pilot }\end{array}$ & Free recall on FCSRT & $\begin{array}{l}\text { Completed no results } \\
\text { yet }\end{array}$ \\
\hline NCT02258152 & PDD & SYN120 & $5 \mathrm{HT}-6 / 5 \mathrm{HT}-2 \mathrm{~A}$ antagonist & $\begin{array}{l}\text { Phase 2, } \\
\text { DB-PC }\end{array}$ & $\begin{array}{l}\text { CDR computerized cognition } \\
\text { battery continuity of attention }\end{array}$ & Negative \\
\hline NCT01701544 & PDD & $\begin{array}{l}\text { DBS of nucleus } \\
\text { basalis of } \\
\text { Meynert }\end{array}$ & Neuromodulation & $\begin{array}{l}\text { Open-label, } \\
\text { pilot }\end{array}$ & $\begin{array}{l}\text { Abbreviated cognitive battery, } \\
\text { safety }\end{array}$ & $\begin{array}{l}\text { Safe but no cognitive } \\
\text { improvement }\end{array}$ \\
\hline NCT02640729 & $\begin{array}{l}\text { DLB or PDD } \\
\text { with VH }\end{array}$ & Nelotanserin & 5HT-2A antagonist & $\begin{array}{l}\text { Phase 2, } \\
\text { DB-PC, } \\
\text { cross-over }\end{array}$ & Safety, UPDRS Part 3 & $\begin{array}{l}\text { Safe/well tolerated but } \\
\text { no significant changes } \\
\text { on endpoints }\end{array}$ \\
\hline NCT03325556 & $\begin{array}{l}\text { DLB or PDD } \\
\text { with } \\
\text { psychosis }\end{array}$ & Pimavanserin & $\begin{array}{l}\text { 5HT-2A inverse agonist/ } \\
\text { antagonist }\end{array}$ & $\begin{array}{l}\text { Phase 3, } \\
\text { time to } \\
\text { event }\end{array}$ & Time to relapse & Positive \\
\hline NCT02708186 & $\begin{array}{l}\text { DLB or PDD } \\
\text { with RBD }\end{array}$ & Nelotanserin & 5HT-2A antagonist & $\begin{array}{l}\text { Phase 2, } \\
\text { DB-PC }\end{array}$ & RBD frequency & Negative \\
\hline
\end{tabular}

Abbreviations: ADAS-Cog Alzheimer's Disease Assessment Scale-Cognitive Subscale, ADCS-CGIC AD Cooperative Study-Clinical Global Impression of Change, CIBIC+ Clinician's Interview-Based Impression of Change plus Caregiver Input, DB-PC double-blind, placebo controlled, DLB dementia with Lewy bodies, ESS Epworth Sleepiness Scale, FCSRT Free and Cued Selective Reminding Test, LBD Lewy body dementia, MoCA Montreal Cognitive Assessment, MWT Maintenance of Wakefulness Test, PDD Parkinson's disease dementia, RBD REM sleep behavior disorder, UPDRS Unified Parkinson's Disease Rating Scale, VH visual hallucinations

have been conducted in PD-MCI, operationalization of MCI-LB research criteria is just beginning [17, 31-33].

Regarding the broad range of LBD symptomatology, the cognitive phenotype includes attentional, executive function, and visuospatial deficits, but memory and naming may also be affected in a subset of patients. Some LBD patients have greater neuropsychiatric, autonomic, or sleep phenotypes, and a subset of people with DLB do not have parkinsonism. Trials focusing on cognitive endpoints may not capture other LBD core or supportive features. Some trials specifically exclude major depression or capture additional LBD symptoms only in secondary or exploratory endpoints (e.g., NPI, Unified PD Rating Scale [UPDRS] Part 3). Detailed descriptions of core and supportive features in LBD trial participants are often lacking. One exception is the DLB donepezil trial by Mori et al. in which frequencies of core features were provided, along with details of suggestive and supportive features [34]. Co-morbidities such as cerebrovascular disease are variably described in LBD trials; such data were provided in the clinical trial for memantine but not rivastigmine [28, 35]. Concomitant medications frequently used in LBD (e.g., cholinesterase inhibitors, dopaminergic medications, antidepressants, and antipsychotics) also vary in how they are handled in study design. Some studies exclude LBD participants taking these medications, whereas others demonstrate variable rates of use, which potentially could influence 
Table 2 Barriers and challenges to developing clinical trials in Lewy body dementia

\begin{tabular}{|c|c|}
\hline Category & Barriers and challenges \\
\hline Trial focus & $\begin{array}{l}\text { - Need for both disease-modifying and symptomatic trials } \\
\text { - Lack of studies focusing on the breadth of LBD symptoms, including non-cognitive outcomes }\end{array}$ \\
\hline Study population & $\begin{array}{l}\text { - Delays in LBD diagnosis } \\
\text { - Heterogeneity of clinical symptomatology } \\
\text { - Co-morbidities (e.g., cerebrovascular disease) } \\
\text { - Concomitant medication use (e.g., cholinesterase inhibitors, antipsychotics, parkinsonian } \\
\text { medications) }\end{array}$ \\
\hline Recruitment and retention & $\begin{array}{l}\text { - Cognitively impaired population } \\
\text { - Lack of under-represented minorities in studies } \\
\text { - Complex and long assessment batteries } \\
\text { - Study procedures (e.g., lumbar puncture, imaging) } \\
\text { - Caregivers with high degrees of burden and stress } \\
\text { - Long travel distances to study centers } \\
\text { - Retention of older adults with combined cognitive, behavioral, and motor symptoms }\end{array}$ \\
\hline Selection of outcome measures & $\begin{array}{l}\text { - Lack of LBD-specific outcome measures } \\
\text { - Existing outcome measures designed more for use in AD trials } \\
\text { - Optimal outcome for different symptoms is uncertain } \\
\text { - Existing outcome measures often lack validated measurement properties for LBD } \\
\text { (e.g., inter-rater reliability, sensitivity to change) }\end{array}$ \\
\hline Study execution & $\begin{array}{l}\text { - Medication effects on attention and alertness } \\
\text { - Cognitive fluctuations, which may affect test performance } \\
\text { - "On" and "off" timing in individuals with Parkinson's disease }\end{array}$ \\
\hline Biomarkers & $\begin{array}{l}\text { - Lack of biomarkers of progression } \\
\text { - Lack of established a-synuclein biomarkers (imaging, biofluid) } \\
\text { - Biomarkers in DLB criteria focus on diagnosis rather than clinical trial use } \\
\text { - Lack of biomarker standardization } \\
\text { - Lack of availability or access to some biomarker studies (e.g., dopaminergic imaging, } \\
\text { polysomnography, cardiac MIBG) }\end{array}$ \\
\hline
\end{tabular}

Abbreviations: $A D$ Alzheimer's disease, $L B D$ Lewy body dementia

outcomes and generalizability of findings. In memantine trials, cholinesterase inhibitors were excluded by Emre et al., but allowed by Aarsland et al. with their use in $47 \%$ of drug and $63 \%$ of placebo groups [28, 36]. Future trials may benefit from addressing a range of LBD symptoms, considering subgroups of LBD based on phenotypes, biomarker profiles, or genotype, as well as accounting for co-morbidities or co-pathologies that may influence cognitive status.

\section{Recruitment and retention}

Recruitment and retention of study subjects are wellknown challenges of clinical research, in general and in LBD. Subjects meeting criteria for many studies are often younger, male, healthier, wealthier, and more likely Caucasian, which may limit generalizability of findings. The study cohort in the Dubois et al. trial of donepezil in PDD, recruiting from 13 countries in Europe, plus Russia, South Africa, Australia, New Zealand, and Canada, was represented by $98 \%$ White, 1\% Black, and $1 \%$ other [37]; similar demographics (98-100\% White) are found in the LBD memantine and rivastigmine trials involving multiple European countries [28, 35]. Strategies for minority recruitment in LBD trials are needed. Subject retention and study completion can be difficult, with completion rates of about $70-80 \%$ in several LBD trials. These aspects can be particularly challenging when trials involve older participants with dementia, behavioral, and motor issues; assessment batteries are long and complex; procedural burden (blood draws, lumbar punctures, imaging) is high; and logistic issues (e.g., transportation, lodging, financial, fatigue) pose challenges. LBD caregivers, who also provide data for clinical trials, often face high degrees of burden and stress. Partnerships with patient advocacy groups and foundations for registries and awareness provide opportunities to help with study recruitment [38]. Considerations for transportation, televisits, or home monitoring may reduce barriers of study enrollment and retention $[39,40]$.

\section{Primary outcome measures}

Determining primary outcome measures for LBD clinical trials include critical decisions such as whether to have a single primary or a co-primary outcome measure and whether to incorporate functional outcome measures or psychosocial aspects such quality of life or caregiver burden. These decisions may depend on the trial's focussymptomatic treatment vs. disease modification, certain clinical features, safety, tolerability, time to event, survival, phase of the trial (e.g., phase 1-4), and design (e.g., open label; double-blind, placebo-controlled trial; or other). Studies for approval of AD drugs typically have 


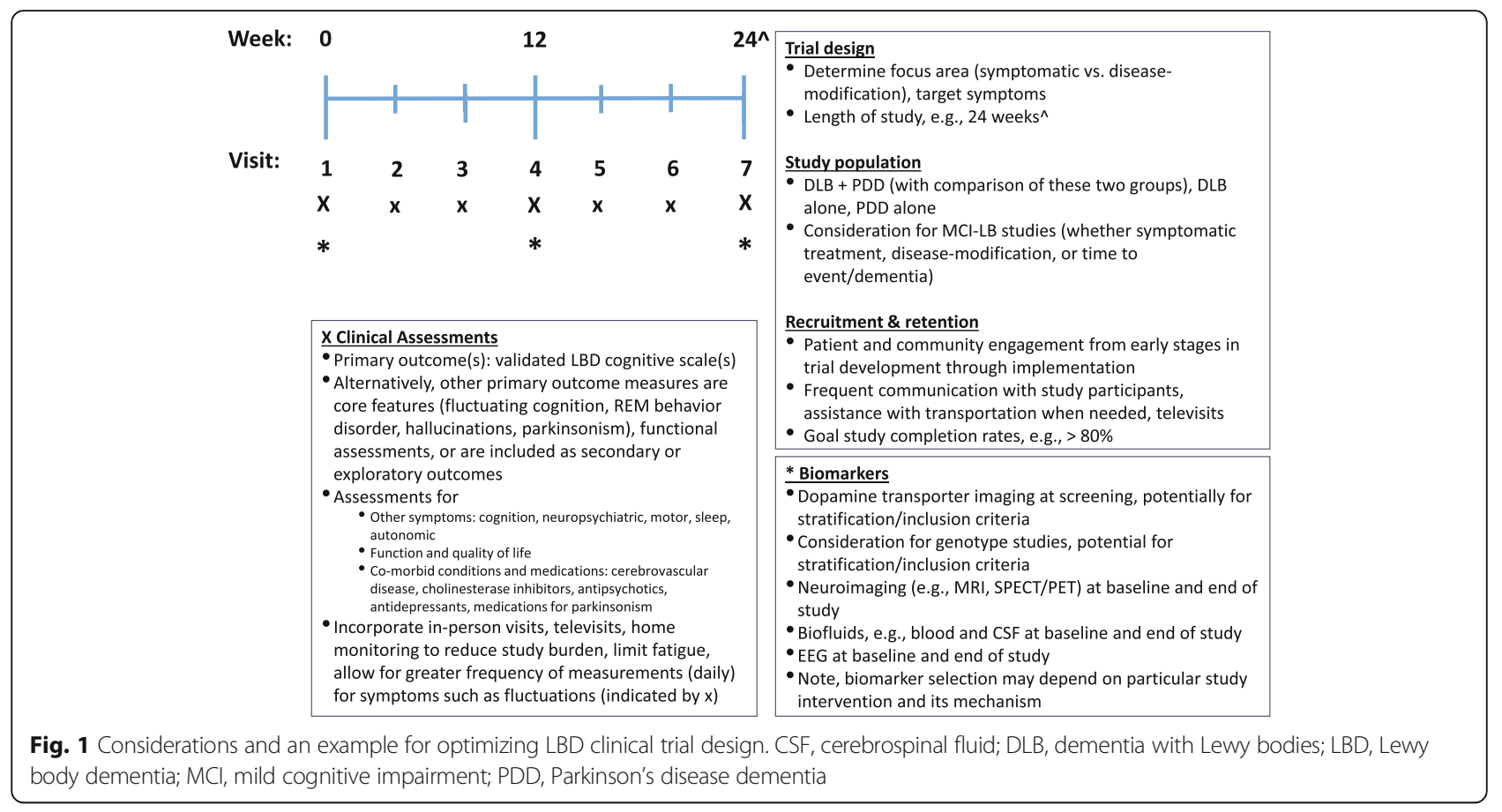

used a co-primary approach to assess global cognitive and functional measures. In 2018, the US FDA issued a new guidance that recognized the challenges in this approach, particularly for early stages of dementia, where drugs may target disease states prior to the onset of overt dementia [41]. This guidance proposed that for those with early stage $\mathrm{AD}$, sensitive neuropsychological tests could be used as a primary endpoint to provide adequate support for drug approval, and some trials could utilize a time to event model for clinically meaningful events. Application of these guidances in LBD trial design awaits exploration and may carry relevance for targeting early stages of LBD including idiopathic RBD, MCI-LB, or PD-MCI $[16,17]$.

Primary endpoints of LBD trials, to date, have largely been AD-centric. Large, double-blind randomized trials for donepezil and rivastigmine in PDD used the AD Assessment Scale-Cognitive Subscale (ADAS-Cog) as the primary endpoint with the co-primary endpoint of the Clinician's Interview-Based Impression of Change plus Caregiver Input $(\mathrm{CIBIC}+)$ or ADCS-CGIC, respectively [35, 37]. Two LBD memantine trials utilized the ADCS-CGIC [28, 36]. The MMSE and CIBIC+ were the primary endpoints in the randomized controlled trial of donepezil in DLB [34], and in another study, with the co-primary of the NPI-2 subscale for hallucinations and fluctuations, which has not been validated as an outcome measure in this form [42]. Several recent or ongoing trials in LBD utilize the Cognitive Drug Research (CDR) Computerized Assessment System, mainly attention scores (NCT03358253 with SYN120, NCT03305809 with LY3154207) [43].
Few LBD clinical trials have examined visual hallucinations, sleep (RBD, hypersomnolence), and motor signs of parkinsonism. Trials for autonomic symptoms, mood disorders, or fluctuations in LBDs are lacking. For those LBD studies of psychosis, primary endpoints vary from motor function (nelotanserin, NCT02640729), time to relapse of psychosis (pimavanserin, NCT03325556), and the NPI-psychosis subscale (MP-101, NCT03044249). A trial of nelotanserin for LBD-related RBD assessed RBD frequency (NCT02708186), and in an open-label, pilot study of armodafinil for hypersomnolence in DLB, primary efficacy measures were the Epworth Sleepiness Score and Maintenance of Wakefulness Test [44]. Studies of zonisamide in DLB for parkinsonism utilized the UPDRS Part 3 as the primary endpoint $[45,46]$.

Opportunities for LBD trial design include having endpoints and measures validated in LBD and that meet regulatory agency clinical trial qualifications. Such measures could be developed through data mining from longitudinal observational studies and clinical trials or from new or modified assessment instruments with appropriate psychometric properties for LBD. This will allow for modeling of effect size and appropriate duration of trials, both of which are critical for power estimates.

\section{Assessments}

Testing for cognitive impairment for LBD trials requires properly validated measures, with strong test-retest reliability, sensitivity to the type of deficits and spectrum of cognitive impairment/dementia in LBD, and robust 
normative data. Decisions about cognitive test batteries need to consider global vs. specific domain assessments, length, burden, fatigue, fluctuations, and motor demands as well as floor and ceiling effects. Study design may factor in use of composite scores, measures of global cognition, and controlling for motor effects, even with computerized tests $[47,48]$.

While scales to elicit neuropsychiatric and autonomic features, collectively or individually, exist in the PD arena, validation in LBD is lacking. Trials must either focus only on selected features or balance the need to be comprehensive using a variety of different scales while minimizing potential study burden. Parkinsonism has typically been measured by the UPDRS Part 3 or MDS-UPDRS Part 3, but these clinical measurements do not fully capture the sensitivity and type of motor symptoms (e.g., gait, balance, falls) in LBDs or everyday motor function at home. Opportunities to assess motor features and response to intervention in broader, more continuous, and reallife environments may include use of quantitative measures and remote assessment with wearable sensor technology $[49,50]$.

Fluctuating cognition and alertness are core features in LBD that have the potential to greatly influence study outcomes, remain poorly understood, and are challenging to measure. To date, there are no established methods by which to account for DLB fluctuations in clinical trials, though several clinical scales, electrophysiological or imaging studies, or reaction time measurements may provide opportunities to assess this [51,52]. Test performance at study visits may be affected by cognitive or physical fatigue, medications that alter attention and alertness, comorbid psychiatric symptoms, orthostatic hypotension, and "on and off" timing in those with PD. Longitudinal data from observational studies and multiple data points obtained in interventional studies may help address these concerns and detect patterns of performance.

\section{Biomarkers and genetics}

Biomarkers in LBD, whether neuroimaging (molecular, structural, functional), fluid-based (blood, cerebrospinal fluid [CSF], urine, or other), or electrophysiological, as well as genetic subtypes of LBDs have the potential to be used in research for patient selection, outcome measures, and target engagement [53]. Biomarkers in the DLB criteria aid in diagnosis and distinction from $\mathrm{AD}$, though these biomarkers vary in their availability for clinical and research use [29]. For PDD diagnosis, the use of biomarkers remains limited to research. Several proteins have been investigated as biomarkers for LBD, including $\alpha$ synuclein, amyloid- $\beta$, and tau, as measured by molecular imaging and biofluids and representing indirect measures of underlying neurodegeneration and pathology. While dopamine transporter scanning has been utilized in some PD trials for inclusion criteria, these scans have not been incorporated into LBD trials for patient selection [54]. Use of dopamine transporter imaging in early LBD (e.g., MCILB) also awaits further study. Stratifying LBD patients in clinical trials by dopaminergic imaging results may not be a simple decision as this may introduce bias towards more parkinsonian phenotypes of LBD. The lack of $\alpha$-synuclein imaging remains a major gap in the field. Although amyloid- $\beta$ PET imaging reveals that about $30-50 \%$ of people with LBD have positive scans, the frequency of positive tau imaging may be lower $[55,56]$. This adds to the pathologic heterogeneity of LBD, since AD copathology is present in about $50 \%$ of autopsied LBD. Moreover, there is evidence of a dose-dependent association with survival [57]. Amyloid- $\beta$ and tau biomarkers have potential diagnostic utility in LBD trials by allowing for subgroup stratification (e.g., LBD with or without co-existing $\mathrm{AD}$ ) as well as in target engagement for disease-modifying trials. Biomarker profiling approaches in LBD would be greatly enhanced by having robust markers of $\alpha$-synuclein pathology.

CSF measures of amyloid- $\beta$ 1-42 (AB42), tau, and phosphorylated-tau have been associated with worse cognitive outcomes in some LBD studies [53]. CSF biomarkers, including $\alpha$-synuclein and amyloid- $\beta$, could be used for study entry criteria and target engagement in LBD trials, though inclusion of lumbar punctures may affect subject enrollment and retention. One challenge is the high degree of variability in biomarker fluid assays including CSF; inter-laboratory variability for assays of $\alpha$-synuclein is about $10 \%$ (range $5-20 \%$ ) [58]. Thus, standardizing fluid analyses is essential. Longitudinal data for many of these biomarkers as well as comparisons between DLB and PDD, and among subgroups or at-risk cohorts (e.g., RBD, MCI), are crucial. Incorporation of amyloid- $\beta$ biomarkers (imaging and/ or CSF) into inclusion criteria is already underway in AD trials, as are trials of anti-amyloid therapeutics [59, 60]. In LBD, one study of memantine incorporated biomarkers, finding that some PDD receiving drug and having high homocysteine levels responded significantly better [61]. Opportunities include partnerships between AD and LBD biomarker efforts, data and sample sharing (e.g., federal- and foundation-funded programs), development and continued follow up of wellcharacterized clinical cohorts with biomarker samples (e.g., PD Biomarker Program, Parkinson's Progression Markers Initiative, NIA AD Centers, DLB consortium), and autopsy studies. 
EEG is recognized as a supportive biomarker in the diagnosis of DLB, with prominent posterior slow-wave activity with periodic fluctuations in the pre-alpha/theta range [13]. Quantitative or visually assessed EEG differentiates DLB from AD with high sensitivity and specificity and may correlate with cognitive changes, fluctuations, and hallucinations in DLB [62, 63]. EEG also may have a role not only in diagnosing MCI-LB, with slower frequencies in pre-alpha and theta ranges compared to healthy controls and intermittent delta activity patterns differentiating MCI-LB from MCI-AD, but also in predicting conversion from MCI-LB to DLB $[64,65]$. While potentially less costly and less invasive than some biomarker studies, use of EEG as a diagnostic or prognostic biomarker for LBD will require increased standardization, understanding of inter-individual variability, integration with imaging and biofluid markers, and larger-scale prospective studies.

Genetic risk factors for both $\mathrm{AD}$ and PD may contribute to the development and symptoms of LBD. Some genetic mutations or polymorphisms (e.g., $A P O E$ locus, $M A P T$, and GBA genes) may influence the presence and severity of cognitive impairment in LBD [66-68]. APOE e4 carrier status has been linked to greater cognitive impairment and co-existing $\mathrm{AD}$ pathology in LBD [57, 67, 68]. To date, these genetic markers have not been utilized in LBD trials. In contrast, $\mathrm{AD} / \mathrm{MCI}$ trials have incorporated genetic mutations (e.g., dominantly inherited AD) or polymorphisms ( $A P O E$ e4 alleles) into trial design. GBA mutations, a susceptibility factor for PD, are found in those with DLB and LBD with AD pathology to a greater degree than in $\mathrm{AD}$ or control participants [67]. Trials targeting GBA carriers in PD are emerging [69]. In addition, GBA may play a role in target engagement for trials. Ambroxol is currently under study in a phase 2 trial of PDD (NCT02914366), examining its effect on the ADAS-Cog and CGIC, with additional measures of MRI, CSF, and Gcase activity in lymphocytes [70].

\section{Conclusions}

In summary, there are challenges but also opportunities for clinical trials in LBD. Advances in our understanding of LBD symptomatology, diagnoses, prodromal stages, longitudinal changes, and pathophysiological mechanisms will enable us to discover new targets and strategies for therapeutic interventions. This approach will enable us to define more biologically homogenous groups of LBD patients for inclusion criteria that can improve efficiency of trials, especially those targeting specific underlying disease mechanisms for $\alpha$-synuclein and/or AD neuropathology. Defining trial focus areas with input from the LBD patient community, along with implementing outcome measures validated in LBD; comprehensive, but not burdensome, test batteries; and biomarkers reflecting key mechanisms of disease are future goals of LBD trials. Mock clinical trials, as performed in frontotemporal lobar degeneration, may provide insight into disease progression and optimal outcome measures [71]. Observational clinical research in PD, PDD, and DLB with harmonized assessments, brain donation for research, and data and biosample sharing are critical. Partnership and consultation across patients, clinicians, researchers, industry, and government agencies on trial design and regulatory guidance regarding FDA will be vital for the future of LBD trials.

\section{Abbreviations}

AD: Alzheimer's disease; ADAS-Cog: AD Assessment Scale-Cognitive Subscale: ADCS-CGIC: AD Cooperative Study-Clinical Global Impression of Change; APOE: Apolipoprotein E; CIBIC+: Clinician's Interview-Based Impression of Change plus Caregiver Input; DLB: Dementia with Lewy bodies;

DSM: Diagnostic and Statistical Manual of Mental Disorders; FDA: Food and Drug Administration; GBA: Beta-glucosidase; IAC: Industry Advisory Council; LBCRS: Lewy Body Composite Risk Score; LBDA: Lewy Body Dementia Association; MAPT: Microtubule-associated protein tau; MCl: Mild cognitive impairment; MCI-LB: Mild cognitive impairment-Lewy body; MMSE: MiniMental State Examination; NACC: National Alzheimer's Coordinating Center; NPI: Neuropsychiatric Inventory; PD: Parkinson's disease; PDD: Parkinson's disease dementia; PD-MCl: Parkinson's disease-mild cognitive impairment; RBD: REM sleep behavior disorder; RCOE: Research Centers of Excellence; UPDRS: Unified PD Rating Scale

\section{Acknowledgements}

We would like to dedicate this manuscript in memory of Daniel I. Kaufer, MD, member of the LBDA Scientific Advisory Council, and Research Centers of Excellence, for his contributions to the LBDA Industry Advisory Council and the field. Dr. Kaufer served as Associate Professor of Neurology and Psychiatry; the Division Chief, Cognitive Neurology and Memory Disorders; the founding Director of the UNC Memory Disorders Program; and Codirector of the Carolina Alzheimer's Network. He passed away on July 2, 2020, after a brief illness. Dr. Kaufer is remembered for his clinical care and research in LBD and frontotemporal degeneration, contributions to the development of important clinical assessment tools, and compassion for his patients and family caregivers.

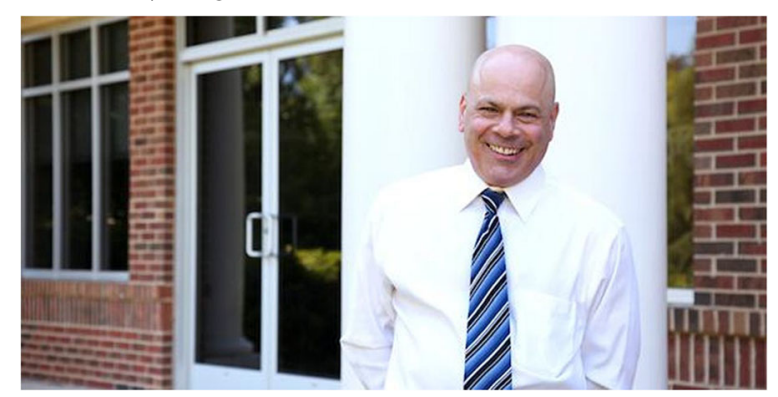

We thank Nina Silverberg, PhD, for the thoughtful discussion on topics covered in this manuscript.

\section{Authors' contributions}

JGG was a major contributor in writing and editing the manuscript. LKF was responsible for integrating the input from all authors and contributed to the writing of the manuscript. MJA, DJ, BB, TJF, DG, JEG, CFL, and KM contributed to the manuscript sections regarding clinical trials, recruitment and retention, assessments, biomarkers, and genetics, and manuscript edits, and all authors contributed to the manuscript content. All authors reviewed and approved the final manuscript. 


\section{Authors' information}

NA

\section{Funding}

The IAC meeting was supported by the LBDA.

\section{Availability of data and materials}

NA

\section{Ethics approval and consent to participate NA}

\section{Consent for publication}

NA

\section{Competing interests}

Goldman-Dr. Goldman has received grant/research funding from Michael J. Fox Foundation and Parkinson's Foundation, served as consultant for Worldwide Med, and has received honoraria from Davis Phinney Foundation, International Parkinson and Movement Disorder Society, and Parkinson's Foundation.

Forsberg-Dr. Forsberg has nothing to disclose.

Boeve-Dr. Boeve has received grant/research funding from the $\mathrm{NIH}$ (AG016574, AG062677, NS100620, AG056639, AG054256, AG050326), the Mayo Clinic Dorothy and Harry T. Mangurian Jr. Lewy Body Dementia Program, and the Little Family Foundation and serves as an investigator for clinical trials sponsored by Biogen, Alector, and EIP Pharma; Scientific Advisory Board of the Tau Consortium.

Armstrong-Dr. Armstrong has received grant/research funding from AHRQ (K08HS24159), NIA P30AG047266, and the Florida Department of Health (grant 20A08) and compensation from the AAN for work as an evidencebased medicine methodology consultant and is on the level of evidence editorial board for Neurology ${ }^{\oplus}$ and related publications (uncompensated). Irwin-Dr. Irwin has received grant/research funding from NIH NS109260, U01-NS100610, R01-AG056014, P30-AG010124, U19-AG062418, and Penn Institute on Aging

Ferman-Dr. Ferman has nothing to disclose.

Galasko_Dr. Galasko has received grant/research funding from NIH/NIA, State of California, and Michael J Fox Foundation and serves as a consultant to Esai, Biogen, Fujirebio, Amprion, vTv Pharmaceuticals, and DSMB for Cognition Therapeutics.

Galvin-Dr. Galvin is the creator of the Lewy Body Composite Risk Score. Kaufer-Dr. Kaufer has nothing to report.

Leverenz-Dr. Leverenz has received grant/research funding from $\mathrm{NIH}$ / NINDS and GE Healthcare and has received consultant fees from Acadia, Eisai, and Sunovion.

Lippa-Dr. Lippa has received clinical trial research support from Acadia and Axovant

Marder-Dr. Marder has received grant/research funding from NIH (U01NS100600, U24NA107168, UL1TR001873, R01NS0736 71, R01LM00986, R01NS-9435, RM1HG007257), Michael J. Fox Foundation, Parkinson's Foundation, CHDI, and Huntington's Disease Society of America.

Abler-Dr. Abler is a full-time employee of Acadia Pharmaceuticals.

Biglan-Dr. Biglan is a full-time employee and has a minor shareholder stake in Eli Lilly and Company.

Irizarry-Dr. Irizarray is a full-time employee of Eisai, Inc

Keller-Mr. Keller is a full-time employee of Acadia Pharmaceuticals.

Munsie-Ms. Munsie is a full-time employee and has a minor shareholder stake in Eli Lilly and Company.

Nakagawa-Mr. Nakagawa is a full-time employee of Eisai Co., Ltd. Taylor-Ms. Taylor is a full-time employee and Senior Director of Research and Advocacy for the Lewy Body Dementia Association.

Graham-Mr. Graham is the Executive Director of the Lewy Body Dementia Association.

Drs. Goldman, Boeve, Armstrong, Irwin, Galasko, Galvin, Kaufer, Leverenz, Lippa, and Marder have received grant funding from the Lewy Body Dementia Association Research Center of Excellence program.

\section{Author details}

${ }^{1}$ Parkinson's Disease and Movement Disorders Program, Shirley Ryan AbilityLab and Departments of Physical Medicine and Rehabilitation and
Neurology, Northwestern University Feinberg School of Medicine, 355 E. Erie Street, Chicago, IL 60611, USA. ²Department of Neurology, Mayo Clinic Rochester, MN, USA. ${ }^{3}$ Department of Neurology, University of Florida College of Medicine, Gainesville, FL, USA. ${ }^{4}$ Department of Neurology, Hospital of the University of Pennsylvania, Philadelphia, PA, USA. ${ }^{5}$ Department of Psychiatry and Psychology, Mayo Clinic, Jacksonville, FL, USA. ${ }^{6}$ Department of Neurosciences, UC San Diego, San Diego, CA, USA. Department of Neurology, University of Miami Miller School of Medicine, Miami, FL, USA. ${ }^{8}$ Department of Neurology, University of North Carolina, Chapel Hill, NC, USA. ${ }^{9}$ Lou Ruvo Center for Brain Health, Neurological Institute, Cleveland Clinic, Cleveland, $\mathrm{OH}$, USA. ${ }^{10}$ Department of Neurology, Thomas Jefferson University, Philadelphia, PA, USA. ${ }^{11}$ Department of Neurology, Taub Institute, Sergievsky Center, Columbia University Irving Medical Center, New York, NY, USA. ${ }^{12}$ Acadia Pharmaceuticals, San Diego, CA, USA. ${ }^{13}$ Neuroscience Research, Eli Lilly and Company, Indianapolis, IN, USA. ${ }^{14}$ Neurology Business Group, Eisai, Inc., Woodcliff Lake, NJ, USA. ${ }^{15}$ Neurology Business Group, Eisai Co., Ltd., Tokyo, Japan. ${ }^{16}$ Lewy Body Dementia Association, S.W., Lilburn, GA, USA.

Received: 24 August 2020 Accepted: 8 October 2020

Published online: 29 October 2020

\section{References}

1. Mueller C, Ballard C, Corbett A, Aarsland D. The prognosis of dementia with Lewy bodies. Lancet Neurol. 2017;16(5):390-8.

2. Vann Jones SA, O'Brien JT. The prevalence and incidence of dementia with Lewy bodies: a systematic review of population and clinical studies. Psychol Med. 2014;44(4):673-83.

3. Corriveau RA, Koroshetz WJ, Gladman JT, Jeon S, Babcock D, Bennett DA, et al. Alzheimer's Disease-Related Dementias Summit 2016: national research priorities. Neurology. 2017:89(23):2381-91.

4. Goldman JG, Weintraub D. Advances in the treatment of cognitive impairment in Parkinson's disease. Mov Disord. 2015:30(11):1471-89.

5. Lee G, Cummings J, Decourt B, Leverenz JB, Sabbagh MN. Clinical drug development for dementia with Lewy bodies: past and present. Expert Opin Investig Drugs. 2019;28(11):951-65.

6. Peterson B, Armstrong M, Galasko D, Galvin JE, Goldman J, Irwin D, et al. Lewy Body Dementia Association's Research Centers of Excellence Program: inaugural meeting proceedings. Alzheimers Res Ther. 2019;11(1):23.

7. Peterson I, Cruz R, Sarr F, Stanley AM, Jarecki J. The SMA Clinical Trial Readiness Program: creation and evaluation of a program to enhance SMA trial readiness in the United States. Orphanet J Rare Dis. 2020;15(1):118.

8. Rose DM, Marshall R, Surber MW. Pharmaceutical industry, academia and patient advocacy organizations: what is the recipe for synergic (win-winwin) collaborations? Respirology. 2015;20(2):185-91.

9. Cummings J, Reiber C, Kumar P. The price of progress: funding and financing Alzheimer's disease drug development. Alzheimers Dement (N Y). 2018:4:330-43.

10. Thomas AJ, Taylor JP, McKeith I, Bamford C, Burn D, Allan L, et al. Development of assessment toolkits for improving the diagnosis of the Lewy body dementias: feasibility study within the DIAMOND Lewy study. Int J Geriatr Psychiatry. 2017:32(12):1280-304.

11. Galvin JE, Duda JE, Kaufer DI, Lippa CF, Taylor A, Zarit SH. Lewy body dementia: the caregiver experience of clinical care. Parkinsonism Relat Disord. 2010;16(6):388-92.

12. Dujardin K, Dubois B, Tison F, Durif F, Bourdeix I, Pere JJ, et al. Parkinson's disease dementia can be easily detected in routine clinical practice. Mov Disord. 2010;25(16):2769-76.

13. McKeith IG, Boeve BF, Dickson DW, Halliday G, Taylor JP, Weintraub D, et al. Diagnosis and management of dementia with Lewy bodies: fourth consensus report of the DLB Consortium. Neurology. 2017:89(1):88-100

14. Emre M, Aarsland D, Brown R, Burn DJ, Duyckaerts C, Mizuno Y, et al. Clinical diagnostic criteria for dementia associated with Parkinson's disease. Mov Disord. 2007;22(12):1689-707 quiz 837

15. American Psychiatric Association. Diagnostic and statistical manual of mental disorders (5th ed.). Arlington, VA; 2013.

16. Litvan I, Goldman JG, Troster Al, Schmand BA, Weintraub D, Petersen RC, et al. Diagnostic criteria for mild cognitive impairment in Parkinson's disease: Movement Disorder Society Task Force guidelines. Mov Disord. 2012;27(3):349-56. 
17. McKeith IG, Ferman TJ, Thomas AJ, Blanc F, Boeve BF, Fujishiro H, et al Research criteria for the diagnosis of prodromal dementia with Lewy bodies. Neurology. 2020;94(17):743-55.

18. Galvin JE. Improving the clinical detection of Lewy body dementia with the Lewy body composite risk score. Alzheimers Dement Diagn Assess Dis Monit. 2015;1(3):316-24.

19. $L B D A$. Comprehensive LBD symptoms checklist. Available from: www.lbda.org.

20. Besser L, Kukull W, Knopman DS, Chui H, Galasko D, Weintraub S, et al. Version 3 of the National Alzheimer's Coordinating Center's Uniform Data Set. Alzheimer Dis Assoc Disord. 2018;32(4):351-8.

21. Thomas AJ, Taylor JP, McKeith I, Bamford C, Burn D, Allan L, et al. Revision of assessment toolkits for improving the diagnosis of Lewy body dementia: the DIAMOND Lewy study. Int J Geriatr Psychiatry. 2018;33(10):1293-304.

22. Taylor J-P, McKeith IG, Burn DJ, Boeve BF, Weintraub D, Bamford C, et al. New evidence on the management of Lewy body dementia. Lancet Neurol. 2020;19(2):157-69.

23. Verny M, Blanc F. Lewy body dementia: therapeutic propositions according to evidence based medicine and practice. Geriatr Psychol Neuropsychiatr Vieill. 2019;17:189-97.

24. Stinton C, McKeith I, Taylor JP, Lafortune L, Mioshi E, Mak E, et al. Pharmacological management of Lewy body dementia: a systematic review and meta-analysis. Am J Psychiatry. 2015;172(8):731-42.

25. Hershey LA, Coleman-Jackson R. Pharmacological management of dementia with Lewy bodies. Drugs Aging. 2019;36(4):309-19.

26. Seppi K, Ray Chaudhuri K, Coelho M, Fox SH, Katzenschlager R, Perez Lloret $S$, et al. Update on treatments for nonmotor symptoms of Parkinson's disease - an evidence-based medicine review. Mov Disord. 2019;34(2):180-98

27. Velayudhan L, Ffytche D, Ballard C, Aarsland D. New therapeutic strategies for Lewy body dementias. Curr Neurol Neurosci Rep. 2017;17(9):68.

28. Emre M, Tsolaki M, Bonuccelli U, Destee A, Tolosa E, Kutzelnigg A, et al. Memantine for patients with Parkinson's disease dementia or dementia with Lewy bodies: a randomised, double-blind, placebo-controlled trial. Lancet Neurol. 2010;9(10):969-77.

29. McKeith IG, Dickson DW, Lowe J, Emre M, O'Brien JT, Feldman H, et al. Diagnosis and management of dementia with Lewy bodies: third report of the DLB Consortium. Neurology. 2005;65(12):1863-72.

30. Graff-Radford J, Boeve BF, Pedraza O, Ferman TJ, Przybelski S, Lesnick TG, et al. Imaging and acetylcholinesterase inhibitor response in dementia with Lewy bodies. Brain. 2012;135(Pt 8):2470-7.

31. Mamikonyan E, Xie SX, Melvin E, Weintraub D. Rivastigmine for mild cognitive impairment in Parkinson disease: a placebo-controlled study. Mov Disord. 2015;30(7):912-8

32. Weintraub D, Hauser RA, Elm JJ, Pagan F, Davis MD, Choudhry A, et al. Rasagiline for mild cognitive impairment in Parkinson's disease: a placebocontrolled trial. Mov Disord. 2016:31(5):709-14

33. Hinson VK, Delambo A, Elm J, Turner T. A randomized clinical trial of atomoxetine for mild cognitive impairment in Parkinson's disease. Mov Disord Clin Pract. 2017;4(3):416-23.

34. Mori E, Ikeda M, Kosaka K, Donepezil DLBSI. Donepezil for dementia with Lewy bodies: a randomized, placebo-controlled trial. Ann Neurol. 2012;72(1):41-52.

35. Emre M, Aarsland D, Albanese A, Byrne EJ, Deuschl G, De Deyn PP, et al. Rivastigmine for dementia associated with Parkinson's disease. N Engl J Med. 2004;351(24):2509-18.

36. Aarsland D, Ballard C, Walker Z, Bostrom F, Alves G, Kossakowski K, et al. Memantine in patients with Parkinson's disease dementia or dementia with Lewy bodies: a double-blind, placebo-controlled, multicentre trial. Lancet Neurol. 2009:8(7):613-8.

37. Dubois B, Tolosa E, Katzenschlager R, Emre M, Lees AJ, Schumann G, et al. Donepezil in Parkinson's disease dementia: a randomized, double-blind efficacy and safety study. Mov Disord. 2012;27(10):1230-8.

38. Watson JL, Ryan L, Silverberg N, Cahan V, Bernard MA. Obstacles and opportunities in Alzheimer's clinical trial recruitment. Health Aff (Millwood) 2014;33(4):574-9.

39. Frank S, Berk S, Hernandez L, Hogarth P, Shill HA, Siddiqi B, et al. Transportation innovation to aid Parkinson disease trial recruitment. Contemp Clin Trials Commun. 2019;16:100449.

40. Tarolli CG, Zimmerman GA, Goldenthal S, Feldman B, Berk S, Siddiqi B, et al. Video research visits for atypical parkinsonian syndromes among Fox Trial Finder participants. Neurol Clin Pract. 2020;10(1):7-14.
41. Administration USFaD. https://www.fda.gov/regulatory-information/searchfda-guidance-documents/alzheimers-disease-developing-drugs-treatmentguidance-industy. 2018.

42. Ikeda M, Mori E, Matsuo K, Nakagawa M, Kosaka K. Donepezil for dementia with Lewy bodies: a randomized, placebo-controlled, confirmatory phase III trial. Alzheimers Res Ther. 2015;7(1):4.

43. Wesnes KA, Aarsland D, Ballard C, Londos E. Memantine improves attention and episodic memory in Parkinson's disease dementia and dementia with Lewy bodies. Int J Geriatr Psychiatry. 2015;30(1):46-54.

44. Lapid MI, Kuntz KM, Mason SS, Aakre JA, Lundt ES, Kremers W, et al. Efficacy, safety, and tolerability of armodafinil therapy for hypersomnia associated with dementia with Lewy bodies: a pilot study. Dement Geriatr Cogn Disord. 2017:43(5-6):269-80.

45. Murata M, Odawara T, Hasegawa K, Kajiwara R, Takeuchi H, Tagawa M, et al. Effect of zonisamide on parkinsonism in patients with dementia with Lewy bodies: A phase 3 randomized clinical trial. Parkinsonism Relat Disord. 2020; 76:91-7.

46. Murata M, Odawara T, Hasegawa K, liyama S, Nakamura M, Tagawa M, et al. Adjunct zonisamide to levodopa for DLB parkinsonism: a randomized double-blind phase 2 study. Neurology. 2018;90(8):e664-e72.

47. Wesnes KA, McKeith I, Edgar C, Emre M, Lane R. Benefits of rivastigmine on attention in dementia associated with Parkinson disease. Neurology. 2005; 65(10):1654-6.

48. Skorvanek M, Goldman JG, Jahanshahi M, Marras C, Rektorova I, Schmand B, et al. Global scales for cognitive screening in Parkinson's disease: critique and recommendations. Mov Disord. 2018;33(2):208-18.

49. Shawen N, O'Brien MK, Venkatesan S, Lonini L, Simuni T, Hamilton JL, et al. Role of data measurement characteristics in the accurate detection of Parkinson's disease symptoms using wearable sensors. J Neuroeng Rehabil. 2020;17(1):52

50. Espay AJ, Hausdorff JM, Sanchez-Ferro A, Klucken J, Merola A, Bonato P, et al. A roadmap for implementation of patient-centered digital outcome measures in Parkinson's disease obtained using mobile health technologies. Mov Disord. 2019;34(5):657-63.

51. Lee DR, Taylor JP, Thomas AJ. Assessment of cognitive fluctuation in dementia: a systematic review of the literature. Int J Geriatr Psychiatry. 2012; 27(10):989-98

52. Matar E, Shine JM, Halliday GM, Lewis SJG. Cognitive fluctuations in Lewy body dementia: towards a pathophysiological framework. Brain. 2020;143(1):31-46.

53. Siderowf A, Aarsland D, Mollenhauer B, Goldman JG, Ravina B. Biomarkers for cognitive impairment in Lewy body disorders: status and relevance for clinical trials. Mov Disord. 2018;33(4):528-36.

54. McKeith I, O'Brien J, Walker Z, Tatsch K, Booij J, Darcourt J, et al. Sensitivity and specificity of dopamine transporter imaging with 1231-FP-CIT SPECT in dementia with Lewy bodies: a phase III, multicentre study. Lancet Neurol. 2007;6(4):305-13.

55. Gomperts SN. Imaging the role of amyloid in PD dementia and dementia with Lewy bodies. Curr Neurol Neurosci Rep. 2014;14(8):472.

56. Gomperts SN, Locascio JJ, Makaretz SJ, Schultz A, Caso C, Vasdev N, et al. Tau positron emission tomographic imaging in the Lewy body diseases. JAMA Neurol. 2016;73(11):1334-41.

57. Irwin DJ, Grossman M, Weintraub D, Hurtig HI, Duda JE, Xie SX, et al. Neuropathological and genetic correlates of survival and dementia onset in synucleinopathies: a retrospective analysis. Lancet Neurol. 2017; 16(1):55-65.

58. Mollenhauer B, Parnetti L, Rektorova I, Kramberger MG, Pikkarainen M, Schulz-Schaeffer WJ, et al. Biological confounders for the values of cerebrospinal fluid proteins in Parkinson's disease and related disorders. J Neurochem. 2016;139(Suppl 1):290-317.

59. Cummings J, Lee G, Mortsdorf T, Ritter A, Zhong K. Alzheimer's disease drug development pipeline: 2017. Alzheimers Dement (N Y). 2017;3(3):367-84

60. Kim D, Kim YS, Shin DW, Park CS, Kang JH. Harnessing cerebrospinal fluid biomarkers in clinical trials for treating Alzheimer's and Parkinson's diseases: potential and challenges. J Clin Neurol. 2016;12(4):381-92.

61. Litvinenko IV, Odinak MM, Mogil'naya VI, Perstnev SV. Use of memantine (akatinol) for the correction of cognitive impairments in Parkinson's disease complicated by dementia. Neurosci Behav Physiol. 2010;40(2):149-55.

62. Bonanni $L$, Thomas A, Tiraboschi P, Perfetti B, Varanese $S$, Onofrj M. EEG comparisons in early Alzheimer's disease, dementia with Lewy bodies and Parkinson's disease with dementia patients with a 2-year follow-up. Brain. 2008;131(Pt 3):690-705. 
63. Law ZK, Todd C, Mehraram R, Schumacher J, Baker MR, LeBeau FEN, et al. The Role of EEG in the Diagnosis, Prognosis and Clinical Correlations of Dementia with Lewy Bodies-A Systematic Review. Diagnostics (Basel). 2020; 10(9):E616.

64. Schumacher J, Taylor JP, Hamilton CA, Firbank M, Cromarty RA, Donaghy $P C$, et al. Quantitative EEG as a biomarker in mild cognitive impairment with Lewy bodies. Alzheimers Res Ther. 2020;12(1):82.

65. van der Zande JJ, Gouw AA, van Steenoven I, van de Beek M, Scheltens P, Stam CJ, et al. Diagnostic and prognostic value of EEG in prodromal dementia with Lewy bodies. Neurology. 2020;95(6):e662-e70.

66. Guerreiro R, Escott-Price V, Darwent L, Parkkinen L, Ansorge O, Hernandez $D G$, et al. Genome-wide analysis of genetic correlation in dementia with Lewy bodies, Parkinson's and Alzheimer's diseases. Neurobiol Aging. 2016; 38:214 e7- e10.

67. Tsuang D, Leverenz JB, Lopez OL, Hamilton RL, Bennett DA, Schneider JA, et al. GBA mutations increase risk for Lewy body disease with and without Alzheimer disease pathology. Neurology. 2012;79(19):1944-50.

68. Tsuang D, Leverenz JB, Lopez OL, Hamilton RL, Bennett DA, Schneider JA, et al. APOE epsilon4 increases risk for dementia in pure synucleinopathies. JAMA Neurol. 2013;70(2):223-8.

69. Sardi SP, Cedarbaum JM, Brundin P. Targeted therapies for Parkinson's disease: from genetics to the clinic. Mov Disord. 2018;33(5):684-96.

70. Silveira CRA, MacKinley J, Coleman K, Li Z, Finger E, Bartha R, et al. Ambroxol as a novel disease-modifying treatment for Parkinson's disease dementia: protocol for a single-centre, randomized, double-blind, placebo-controlled trial. BMC Neurol. 2019;19(1):20

71. Knopman DS, Kramer JH, Boeve BF, Caselli RJ, Graff-Radford NR, Mendez MF, et al. Development of methodology for conducting clinical trials in frontotemporal lobar degeneration. Brain. 2008;131(Pt 11):2957-68.

\section{Publisher's Note}

Springer Nature remains neutral with regard to jurisdictional claims in published maps and institutional affiliations. 